\title{
UJI KEAMANAN KOMUNIKASI VOIP MENGGUNAKAN SISTEM KEAMANAN SRTP-TLS PADA JARINGAN NIRKABEL
}

\author{
Tri Febriana Handayani ${ }^{1}$, Pande Ketut Sudiarta ${ }^{2}$, I Made Oka Widyantara ${ }^{3}$ \\ ${ }^{123}$ Program Studi Teknik Elektro, Fakultas Teknik, Universitas Udayana \\ Email : Febrianahandayani12@gmail.com ${ }^{1}$, Sudiarta@unud.ac.id²² , \\ Oka.widyantara@unud.ac.id ${ }^{3}$
}

\begin{abstract}
ABSTRAK
VoIP merupakan suatu teknologi yang digunakan untuk berkomunikasi suara jarak jauh secara langsung dengan menggunakan jalur komunikasi data menggunakan protocol TCPIIP. Namun pada dasarnya komunikasi VolP tidak menjamin keamanan data saat melakukan komunikasi. Sistem keamanan sangat penting ditambahkan dalam komunikasi VolP untuk menjaga kerahasiaan komunikasi, sehingga komunikasi yang dilakukan tidak bisa direkam dan diputar ulang. Untuk membangun sebuah keamanan saat berkomunikasi VolP,maka pada penelitian ini ditambahkan sebuah sistem keamanan SRTP-TLS. Penelitian ini dilakukan pada jaringan nirkabel dengan membandingkan keamanan data komunikasi saat menggunakan sistem keamanan SRTP-TLS dan tanpa menggunakan sistem keamanan.
\end{abstract}

Kata Kunci: Nirkabel, Sistem Keamanan, VolP

\section{ABSTRACT}

VolP is a technology used to communicate voice remotely and directly using data communication lines with TCP / IP protocol. But basically, VoIP communication does not guarantee data security when doing communication. A very important security system is added in VolP communications to maintain the confidentiality of communication, so that communication can not be recorded and played back. To build a security when communicating VoIP, then in this study added an SRTP-TLS security system. The study was conducted on wireless networks by comparing the security of data communications when using the SRTP-TLS security system and without using a security system.

Keywords: Wireless, Security System, VolP

\section{PENDAHULUAN}

VolP ialah teknologi yang dapat melewatkan data suara, video dan data yang berbentuk paket memakai jaringan IP. Jaringan IP merupakan jaringan komunikasi data (packet-switch), jadi dalam berkomunikasi memanfaatkan jaringan IP atau Internet. VolP menjadi media untuk berkomunikasi, tetapi dalam suatu jaringan. Voice dari user akan diubah dalam bentuk digital dan dikirimkan bentuk paket data secara real time [1]. Jaringan yang dimanfaatkan berupa internet atau intranet. Sinyal suara analog. Dengan berkomunikasi menggunakan layanan VoIP, banyak keuntungan yang didapatkan, salah satu keuntungannya yaitu konsumsi biaya yang lebih sedikit untuk sambungan langsung jarak jauh (SLJJ). [2] Karena penggunaan jalur internet, biaya hanya pada biaya internet. Dengan dua lokasi yang sudah dihubungkan internet, maka biaya percakapan menjadi sangat rendah [3].

Dengan terbukanya sistem komunikasi VolP mengakibatkan semua orang mampu mempelajari, menyadap dan mengembangkan VolP. Dalam pengoperasiannya, layanan VolP tidak menjamin keamanan data paket pada setiap komunikasi suara. Hal ini memungkinkan dilakukannya aksi penyadapan pada isi komunikasi VolP [4]. Untuk mengatasi kerentanan ini, maka salah satu solusinya adalah dengan mengimplementasi sistem keamanan pada komunikasi VolP. Sistem keamanan yang dapat digunakan adalah Secure Real Time Transport Protocol (SRTP-TLS).

2. KAJIAN PUSTAKA 
Teori-teori penunjang yang digunakan dalam penelitian ini adalah sebagai berikut.

\section{$2.1 \quad$ VolP (Voice Over Internet Protocol)}

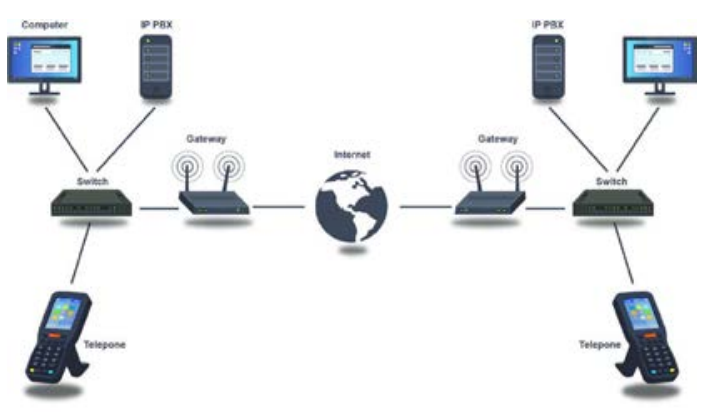

Gambar 1 Diagram VoIP[6]

VolP ialah teknologi yang dapat melewatkan data suara, video dan data yang berbentuk paket memakai jaringan IP [7]. Jaringan IP merupakan jaringan komunikasi data (packet-switch), jadi dalam berkomunikasi memanfaatkan jaringan IP atau Internet [6]. VolP menggunakan layanan internet untuk berkomunikasi seperti menggunakan telepon pada umumnya dengan pengguna VoIP dimana dan kapan saja. Teknologi layanan komunikasi VolP mampu melakukan percakapan telepon dengan jalur komunikasi data dalam jaringan (networking).

Prinsip kerja dari layanan komunikasi VolP yaitu mengubah suara masukan berbentuk analog yang didapatkan dari mikropon pada PC atau softphone menjadi sebuah paket data berbentuk digital, kemudian dari PC atau softphone dilewatkan melintasi router, dan dikiriman menggunakan sebuha jaringan internet yag kemudian diterima oleh user lain sebagai tempat tujuan melalui media yang sama. Prinsip kerja VolP digambarkan pada Gambar 1.

Kualitas suara dari layanan komunikasi VolP tidak jauh berbeda dengan telepon konvensional lainnya, namun kualitas tetap bergantung pada kualitas jaringan telekomunikasi yang sedang digunakan. VoIP mampu diuraikan dengan sederhana sebagai salah satu komunikasi yang memanfaatkan teknologi dengan mengubah suara menjadi bentuk sinyal digital untuk kemudian dikorempresi di beberapa bagian, tanpa harus mengurangi isi dari informasi. Payload ini akan dibagi menjadi paket-paket Internet Protocol (IP) yang selanjutnya ditransmisikan melalui jaringan internet, lalu proses sebaliknya dilakukan di sisi user penerima [8].

\subsection{Secure Real Time Transport Protocol (SRTP)}

Secure Real Time Transport Protocol (SRTP) merupakan protokol standar yang digunakan untuk profile dari Real Time Protocol (RTP). Protokol ini merupakan penyedia autentikasi pesan enkripsi, dan integritas data bagi data RTP. SRTP menyediakan layanan encryption pada RTP yang bertujuan memberikan sistem keamanan data dengan autentikasi pesan enkripsi dan integritas data, serta perlindungan terhadap playback dengan data RTP. Pengembangan SRTP memanfaatkan algoritma Advanced Encryption Standart (AES) sebagai metode enkripsi untuk transmisi data. Pengimplementasian SRTP memiliki 2 mode, yaitu Segmented Integer Counter, dan AES. SRTP juga dapat diimplementasikan pada mode null cipher, mode null cipher adalah sebuah mode pengiriman data yang tidak terlindungi algoritma enkripsi. Pada kenyataannya SRTP hanya mengenkripsi payload (audio dan video) untuk kerahasiaan. SRTP pada komunikasi VoIP memiliki fungsi untuk mengenkripsi komunikasi data VolP. Hal ini bertujuan untuk memastikan jaminan aspek privacy dan integrity. SRTP merupakan algoritma enkripsi yang dimanfaatkan khusus sebagai komunikasi VoIP. SRTP digunakan sebagai enkripsi media stream yang mengakibatkan payload gagal dibaca saat terjadi trafik capturing. Pada SRTP terjadi autentikasi pengiriman untuk mengantisipasi penyadapan identitas namun validasi integrity digunakan untuk mengantisipasi modifikasi pesan yang dikirimkan [4].

Cara kerja SRTP sama dengan RTP, yaitu dengan mendukung dan mengupayakan komunikasi VolP dapat berjalan secara real-time. Namun, pada format protokol SRTP ditambahkan SRTP message untuk memberikan fasilitas 
enkripsi. Sebelum membangun komunikasi VolP, dilakukan pertukaran kunci master terlebih dahulu antar dua client yang berkomunikasi. Kunci master dapat dibangun menjadi dua kunci sesi, diantaranya kunci sesi enkripsi dan kunci sesi autentikasi. Kunci enkripsi digunakan untuk mengenkripsi data VolP sehingga informasi tidak didapatkan secara langsung atau tidak berupa plaintext. Sedangkan kunci autentikasi berfungsi sebagai validasi data dan menjamin penerima adalah tujuan yang benar. Hal ini bertujuan untuk mencegah pemalsuan identitas. Setelah terjadi pertukaran kunci, kunci-kunci tersebut akan digunakan untuk mengenkripsi data sebelum dikirimkan. Pada waktu tertentu kunci sesi ini akan berubah-ubah secara random [5].

\subsection{Transport Layer Security (TLS)}

Transport Layer Security (TLS) dan Secure Socket Layer (SSL) adalah protokol cryptographic berfungsi untuk mengamankan komunikasi di internet (web browsing, email, internet facing, dan instant messaging). Aplikasi dapat berkomunikasi untuk melewati jaringan lain dengan TLS guna mencegah aktifitas penyadapan (eavesdropping), perusakan (tampering) dan pemalsuan pesan (message forgery). Authentication end point dan keleluasaan komunikasi pribadi pada jaringan internet dengan menggunakan cryptography disediakan oleh TLS (Transport Layer Security) [9].

authentikasi pengirim dan penerima yang telah terdeteksi oleh server (kepastian pengenalan) disebut juga sebagai authentication timbal balik. Authentication ini membutuhkan public key infrastructure (PKI) yang menyebar ke klien, kecuali pada TLS-PSK atau protokol Secure Remote Password (SRP) digunakan sebagai penyedia authentication timbal balik yang kuat tanpa perlu mengirimkan PKI. TLS menggunakan tiga tahap dasar yaitu [10]:

1. Peer negosiasi untuk support algoritma

2. Penukaran kunci dan authentication

3. Enkripsi kode symmetric dan perlu pesan authentication

Klien TLS dan server bernegosiasi dengan menggunakan prosedur handshaking. Berbagai parameter yang digunakan untuk tetap berkoneksi disetujui klien dan server pada saat proses handshake. Proses handshake dapat dijabarkan sebagai berikut.

1. Handshake terjadi saat klien meminta server TLS mengamankan koneksi dan menampilkan ciphers (berupa bilangan biner/bahasa mesin) dan hash function.

2. Dari daftar ini, server meminta kembali chipher (berupa bilangan biner/bahasa mesin) dan hash function kemudian memberitahukan keputusannya kepada klien.

3. Identifikasinya dalam bentuk sertifikat digital yang berisi authory dan enkripsi kunci server public dikembalikan oleh server.

Klien diizinkan menghubungi server untuk meyakinkan sertifikat asli sebelum melanjutkannya kembali. Enkripsi klien diacak dengan kunci public untuk menghasilkan kunci enkripsi dan deskripsi di kedua belah pihak. Ini mengakibatkan proses handshake, awal koneksi, dan akhir koneksi terjamin keamanannya. Jika langkah-langkah tersebut gagal, handshake TLS gagal maka koneksi tidak dapat dibangun.

\subsection{Softphone}

Selain dalam bentuk hardware, perangkat telepon juga bisa berbentuk software. Contoh software yang digunakan untuk komunikasi VolP adalah softphone. Softphone adalah aplikasi client VolP yang dapat mendigitalisasi data suara dalam bentuk paket data untuk ditransmisikan melalui jaringan. Pesan yang ditransmisikan dapat berupa voice maupun video.

\subsection{FreePBX}

FreePBX merupakan aplikasi untuk pengontrolan jaringan IP telepon yang mengkonfigurasi web GUI, sehingga lebih mudah untuk mengkonfigurasi Asterisk.

\subsection{Cain and Abel}

Sniffer atau network analyzer merupakan software atau hardware yang berfungsi untuk menghalangi dan mencatat semua trafik sebuah jaringan. Sniffer juga berfungsi untuk menangkap seluruh trafik paket data pada jaringan. Pada penelitian 
ini sniffer yang digunakan adalah Cain and Abel.

\section{METODOLOGI PENELITIAN}

Skenario penelitian digambarkan pada Gambar 2. Pada Gambar 2, terlihat bahwa ada 2 buah klien dengan masingmasing klien menggunakan PC yang sudah ter-install softphone sebagai software untuk komunikasi suara. Codec yang digunakan masing-masing klien adalah G. 711. Layanan VolP disediakan oleh server VoIP yaitu FreePBX. Agar pengujian keamanan dapat dilakukan, maka pada jaringan sistem ini dipasang sebuah aplikasi yang dapat melakukan penyadapan terhadap komunikasi yang dilaukan berupa software Cain and Abel.

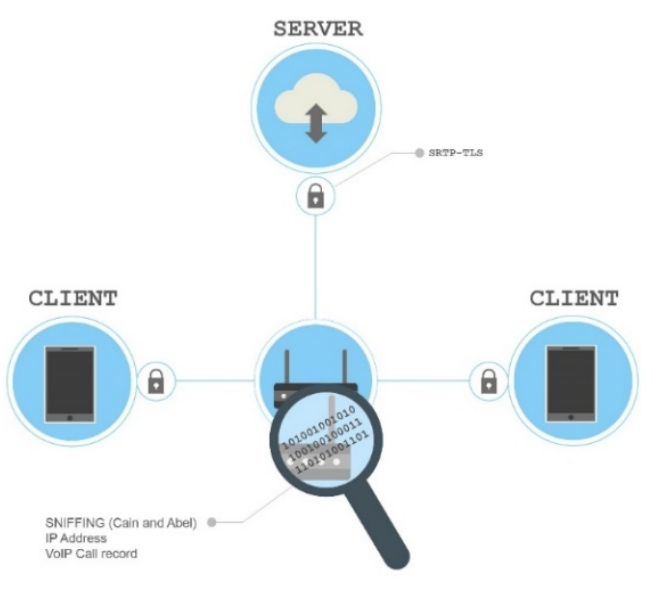

Gambar 2 Diagram Skenario Penelitian

Proses Sniffing dimulai dengan meng-input voice melalui microphone. Pada perangkat suara atau voice akan langsung mengalami proses enkripsi (SRTP-TLS). Seluruh proses ini terjadi pada sisi client hingga ditranmisikan ke sisi server. Pada sisi server, data voice yang telah dienkripsi akan ditransmisikan (Call Prossesing) kembali ke sisi client tujuan (IP tujuan). Sebelum voice menjadi output oleh microphone, data akan mengalami proses deskripsi agar data sesuai dengan data awal sebelum dienkripsi. Proses sniffing dapat terjadi pada jalur IP sumber ataupun IP tujuan. Dengan proses sniffing akan didapatkan rekaman suara yang masih terenkripsi. Blok diagram proses sniffing tersebut digambarkan pada Gambar 3.

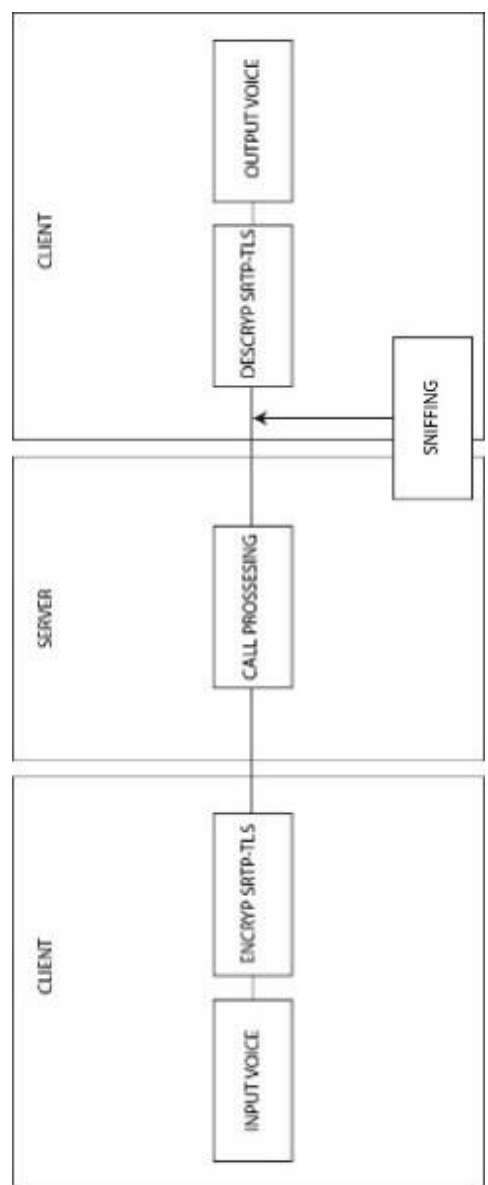

Gambar 3 Blok Diagram Proses Sniffing

Faktor yang menentukan keamanan pada sebuah komunikasi menggunakan SRTP-TLS adalah dapat atau tidaknya sebuah percakapan direkam dan diputar kembali. 


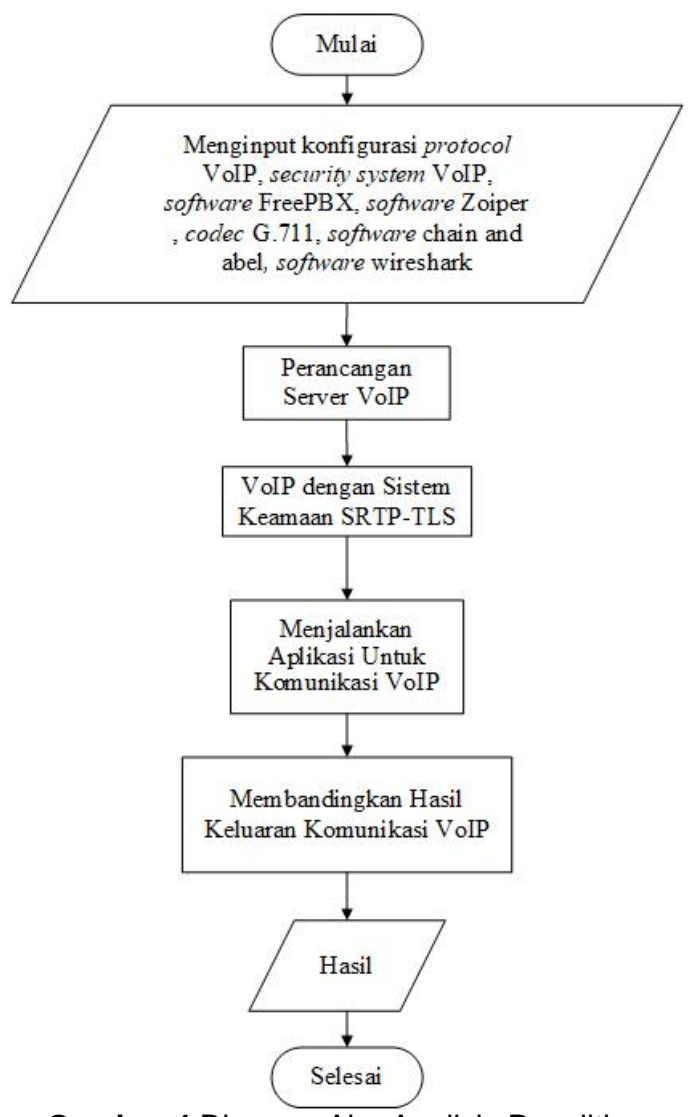

Gambar 4 Diagram Alur Analisis Penelitian Dengan SRTP-TLS

Gambar 4 merupakan alur analisis. Sistem dimulai dengan memberikan inputan konfigurasi iprotocol VolP, security system VolP, software, FreePBX, software Cain and Abel. Kemudian melakukan perancangan pada software FreePBX sebagai server VolP dengan mengimplementasikan sistem keamanan SRTP-TLS dan menggunakan codec G7.11. jika server VoIP telah menggunakan sistem keamanan SRTP-TLS, maka sebuah komunikasi VoIP dengan sistem keamanan SRTP-TLS akan terbentuk. Analisis dilakukan dengan cara membandingkan keluarkan komunikasi VolP berupa data voice menggunakan software Cain and Abel. Jika server VolP tidak menggunakan sistem keamanan SRTP-TLS, maka sebuah komunikasi tanpa sistem keamanan akan terbentuk. Yang kemudian hasil masing-masing keluaran data voice pada komunikasi VolP dengan sistem keamanan SRTP-TLS dengan tanpa sistem keamanan akan dibandingkan, apakah hasil keluaran data voice dapat direkam dan diputar kembali. Kemudian sistem akan mengakhiri proses.

\section{HASIL DAN PEMBAHASAN}

Hasil dan pembahasan pada penelitian ini akan dijabarkan sebagai berikut.

\subsection{Pengujian Keamanan SRTP- TLS Pada Jaringan Nirkabel}

Pada pengujian yang dilakukan menggunakan sistem keamanan SRTPTLS pada jaringan nirkabel, komunikasi dapat direkam namun hasil rekam yang didapatkan hanya menampilkan suara noise. Hal tersebut terjadi karena sistem keamanan SRTP yang sudah diimplementasikan pada komunikasi yang sedang dibangun mengenkripsi payload. SRTP memiliki fitur enkripsi pada profil RTP yang berfungsi untuk menyediakan sistem keamanan data dengan autentikasi dan integritas pesan, dan perlindungan terhadap playback (diputar kembali). Kemungkinkan klien untuk mengautentikasi server dan opsional server untuk mengautentikasi klien dienkripsi oleh TLS.

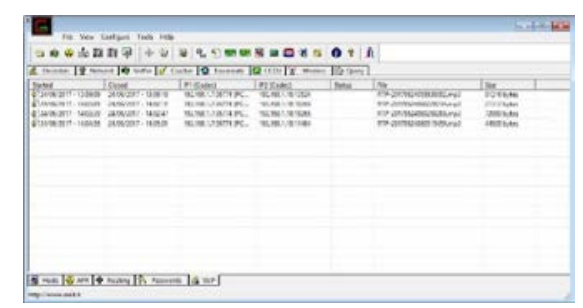

Gambar 5 Hasil Rekaman Komunikasi pada Cain and Abel

Gambar 5 merupakan beberapa hasil rekaman komunikasi yang menggunakan sistem keamanan SRTPTLS, dan ditampilkan dalam software Cain and Abel.

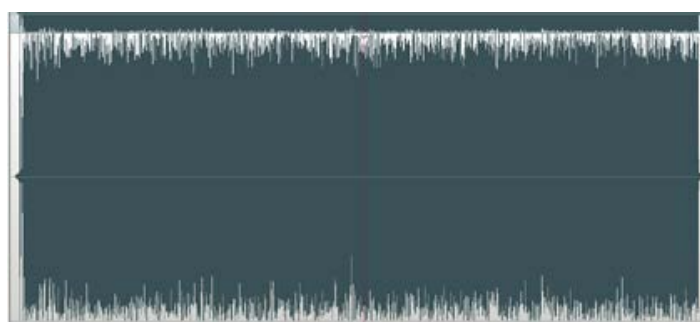

Gambar 6 Tampilan hasil rekam voice SRTPTLS 
Gambar 6 merupakan spektrum suara hasil rekaman komunikasi yang menggunakan sistem keamanan SRTPTLS. Terlihat spektrum suara tidak berada di garis tengah, dan jika diputar kembali, suara yang dihasilkan hanya noise.

Pada pengujian sniffing menggunakan Cain and Abel didapatkan hasil bahwa komunikasi VolP dapat dilakukan.

\subsection{Pengujian Keamanan TLS Pada Jaringan Nirkabel}

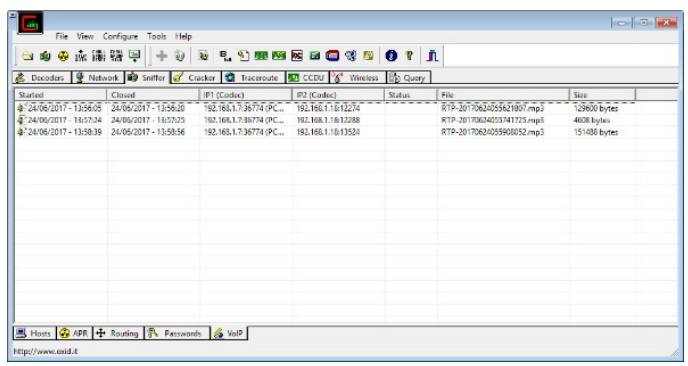

Gambar 7 Hasil Rekaman Komunikasi pada Cain and Abel

Gambar 7 merupakan beberapa hasil rekaman komunikasi yang menggunakan sistem keamanan TLS, dan ditampilkan dalam software Cain and Abel.

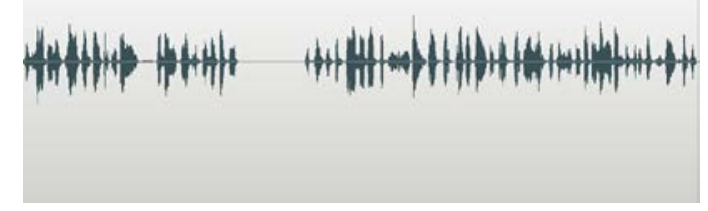

Gambar 8 Tampilan hasil rekam voice TLS

Gambar 8 merupakan spektrum suara hasil rekaman komunikasi yang menggunakan sistem keamanan TLS. Terlihat spektrum suara berada di garis tengah, dan jika diputar kembali, suara yang dihasilkan adalah suara ketika komunikasi berlangsung.

$$
\text { Pada pengujian sniffing }
$$

menggunakan Cain and Abel didapatkan hasil bahwa komunikasi VolP dapat dilakukan namun membutuhkan waktu yang lebih lama untuk pembangunan komunikasi dikarenakan prosedur handshaking yang harus menyetujui berbagai parameter yang digunakan untuk membangun komunikasi, pada pengujian yang dilakukan menggunakan sistem keamanan TLS bisa direkam dan diputar kembali, namun kualitas suara rekaman tidak baik, ini dikarenakan pengaruh dari jaringan nirkabel yang digunakan. Karena jaringan nirkabel mempunyai sifat yang fluktuatif atau tidak stabil. Jika pada saat melakukan komunikasi jaringan yang digunakan baik, maka kualitas suara yang dihasilkan relatif baik, dan begitu sebaliknya.

Hal tersebut terjadi karena sistem keamanan TLS merupakan protokol yang menyediakan komunikasi privasi dan keamanan antara dua aplikasi berkomunikasi melalui jaringan. Sesuai dengan penjabaran sistem keamanan TLS yaitu mengenkripsi komunikasi dan memungkinkan klien untuk mengotentikasi server dan opsional server untuk mengotentikasi klien.

\subsection{Pengujian Tanpa Sistem Keamanan Pada Jaringan Nirkabel}

Pada komunikasi VolP yang dilakukan tanpa menggunakan sistem keamanan, didapatkan hasil komunikasi VoIP bisa melakukan panggilan yang juga dapat di rekam tanpa adanya masalah. Karena komunikasi VolP yang dilakukan pada pengujian ini tanpa menggunakan sistem keamanan, maka seluruh komunikasi dapat di-sniffing menggunakan Cain and Abel.

Hasil sniffing tersebut berupa sebuah rekaman komunikasi dan dapat diputar dengan baik. Pengujian tanpa sistem keamanan yang dilakukan sesuai dengan latar belakang pada penelitian ini yaitu dalam pengoperasiannya, layanan komunikasi VolP tidak menjamin keamanan data paket setiap dilakukannya sebuah komunikasi. 


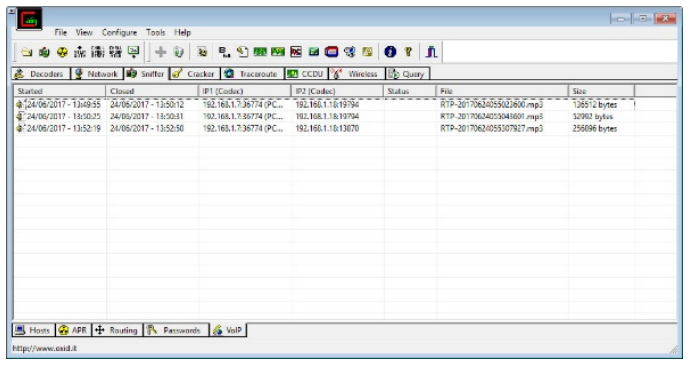

Gambar 9 Hasil Rekaman Komunikasi pada Cain and Abel

Gambar 9 merupakan beberapa hasil rekaman komunikasi tanpa menggunakan sistem keamanan dan ditampilkan dalam software Cain and Abel.

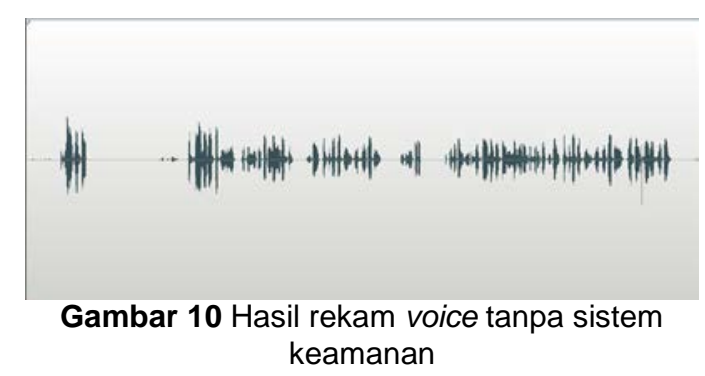

Gambar 10 merupakan spektrum suara hasil rekaman komunikasi tanpa menggunakan sistem keamanan. Terlihat spektrum suara berada di garis tengah, dan jika diputar kembali, suara yang dihasilkan adalah suara ketika komunikasi berlangsung.

Dari masing-masing pengujian menggunakan 3 kondisi, yaitu: pengujian dengan sistem keamanan SRTP-TLS, pengujian dengan sistem keamanan TLS, pengujian tanpa sistem keamanan, didapatkan hasil sebagai berikut:

Tabel 1 Hasil Seluruh Pengujian Keamanan Menggunakan Jaringan Nirkabel

\begin{tabular}{|c|c|}
\hline Pengujian & Hasil \\
\hline $\begin{array}{c}\text { Sistem keamanan } \\
\text { SRTP-TLS }\end{array}$ & $\begin{array}{c}\text { Komunikasi bisa } \\
\text { direkam, namun tidak } \\
\text { bisa diputar kembali } \\
\text { (berbentuk noise) }\end{array}$ \\
\hline $\begin{array}{c}\text { Sistem keamanan } \\
\text { TLS }\end{array}$ & $\begin{array}{c}\text { Komunikasi bisa } \\
\text { direkam dan bisa di- } \\
\text { putar kembali }\end{array}$ \\
\hline Tanpa sistem & Komunikasi bisa \\
keamanan & $\begin{array}{c}\text { direkam dan bisa di- } \\
\text { putar kembali }\end{array}$ \\
\hline
\end{tabular}

Pada pengujian yang dilakukan menggunakan sistem keamanan SRTP. TLS, komunikasi dapat direkam namun hasil rekam yang didapatkan hanya menampilkan suara noise. Hal tersebut terjadi karena sistem keamanan SRTP yang sudah diimplementasikan pada komunikasi yang sedang dibangun mengenkripsi payload untuk kerahasiaan. Sedangkan TLS mengenkripsi komunikasi dan memungkinkan klien untuk mengautentikasi server.

Pada komunikasi VolP yang dilakukan menggunakan jaringan nirkabel dengan sistem keamanan TLS didapatkan hasil bahwa komunikasi VolP dapat dilakukan namun membutuhkan waktu yang lebih lama untuk pembangunan komunikasi dikarenakan prosedur handshaking yang harus menyetujui berbagai parameter yang digunakan untuk membangun komunikasi. Pada pengujian yang dilakukan menggunakan sistem keamanan TLS bisa direkam dan diputar kembali, namun kualitas suara rekaman tidak baik, ini dikarenakan pengaruh dari jaringan nirkabel yang digunakan. Karena jaringan nirkabel mempunyai sifat yang fluktuatif atau tidak stabil. Jika pada saat melakukan komunikasi jaringan yang digunakan baik, maka kualitas suara yang dihasilkan relatif baik, dan begitu sebaliknya.

Sedangkan pada komunikasi VolP menggunakan jaringan nirkabel yang dilakukan tanpa menggunakan sistem keamanan, didapatkan hasil komunikasi VolP bisa melakukan panggilan yang juga dapat di rekam tanpa adanya masalah. Karena komunikasi VolP yang dilakukan pada pengujian ini tanpa menggunakan sistem keamanan, maka seluruh komunikasi dapat di-sniffing berupa sebuah rekaman komunikasi dan dapat diputar dengan baik.

\section{KESIMPULAN}

Penambahan sistem keamanan SRTP-TLS pada komunikasi VolP di jaringan nirkabel terbukti aman. Keamanan tersebut dapat dibuktikan dari komunikasi yang dilakukan saat menggunakan sistem keamanan SRTP-TLS, tidak dapat direkam dan diputar ulang. Berbeda halnya jika 
tidak menggunakan sistem keamanan dan hanya menggunakan sistem keamanan TLS, komunikasi VolP yang dilakukan bisa direkam dan diputar ulang dengan mudahnya. Beberapa kualitas komunikasi yang tidak baik, dipengaruhi oleh jaringan nirkabel yang digunakan mempunyai sifat yang fluktuatif atau tidak stabil.

ini, maka dapat dilakukan dengan mengujicobakan codec dan protocol VolP yang berbeda, serta dengan perbandingan jarak.

\section{DAFTAR PUSTAKA}

[1] Irwansyah, E. \& Jurike V, M,. 2014. "Pengantar Teknologi Informasi," Yogyakarta : Deepublish. 2014.

[2] Zaki, A. "Berkomunikasi Murah Via Internet". Elex Media Komputindo. 2008

[3] Zaki, A. SmitDev Community. "Berkomunikasi Murah Via Internet." Elex Media Komputindo. 2008

[4] Kurniawan, FM. 2014. "Implementasi SRTP-TLS Pada VoIP" Diakses pada 6 Desember 2016. <ilmukomputer.com>

[5] Kalwar, S, K. Khan, M. "SECURED REAL TIME TRANSPORT PROTOCOL (SRTP)". Lappeenrannan University Of Technology, Department Of Information Technolog. 2007

[6] Tharom, T. "Teknis dan Bisnis VolP". Jakarta : PT. Elex Media Komputindo. 2002

[7] Iskandarsyah, M. "Cara Mudah Membangun Jaringan VolP". Bandung : Kawan Pustaka. 2003

[8] Astriani, Dwiarum. 2013. "Teknologi VoIP". Diakses Juli 2017. $<$ http://ilmukomputer.org/2013/01/31/te knologi-voip/>.

[9] Bilien, J. et al. "Secure VolP: Call Establishment and Media Protection". Royal Institute of Technology (KTH). Stockholm, Sweden. 2004

[10] Ariyus, Dony. " KRIPTOGRAFI Keamanan Data dan Komunikasi". Graha IImu. 2006 